УДК: 377.018.43:[37.016:796]

DOI:

Анна Багорка, кандидат педагогічних наук, викладач ВСП “Економіко-правничий фаховий коледж Запорізького національного університету”,

Олена Есаулова, керівник фізичного виховання ВСП "Економіко-правничий фаховий коледж Запорізького національного університету”

\title{
РІЗНОВИДИ ФОРМ ДИСТАНЦЙНИХ ЗАНЯТЬ 3 ФАХОВИХ ДИСЦИПЛІН СПЕЦІАЛЬНОСТІ ФІЗИЧНА КУЛЬТУРА І СПОРТ
}

У статті розглядаються основні технології дистанційного навчання, викладання фахових дисииллін онлайн для здобувачів закладів освіти за спеціальністю “фізична культура і спорт”. Проведено огляд теоретичних прачь та практичних розробок вітчизняних вчених, який свідчить про наявність як об'єктивних недоліків, пов'язаних з якістю інтернетзв'язку, нестачею місия для виконання рухових вправ тощо, так $i$ певних суб'єктивних причин, серед яких зниження мотивації при вивченні теоретичного матеріалу, одноманітність форм і методів викладання. Запропоновано форми проведення занять, які сприяють зацікавленості та, відповідно, підвищенню якості знань з фахових дисциплін.

Ключові слова: дистаниійні технології; фахові дисципліни; форми онлайн занять; фізична культура $i$ cnopm.

Jim. 10.

Anna Bahorka, Ph.D.(Pedagogy), Lecturer of College of Economics and Law of Zaporizhzhia National University

Olena Esaulova, Head of Physical Education of College of Economics and Law of Zaporizhzhia National University

\section{VARIETIES OF FORMS OF DISTANCE LEARNING IN THE PROFESSIONAL DISCIPLINES OF PHYSICAL CULTURE AND SPORTS}

The article considers the main technologies of distance learning for students of higher professional education. Modern information technologies open new perspectives to increase the efficiency of the educational process. There are many benefits of distance learning, such as flexibility - the ability to present the material, according to the individual abilities of students; relevance - the possibility of introducing the latest pedagogical, psychological, methodological ideas; interactivity - the active communication between students of the group and teacher, which significantly increases motivation to learn, improves learning; no geographical restrictions on education etc.

In addition to general online technologies, the teaching of professional subjects for future specialists in physical culture and sports has its own characteristics. Professional training of such specialists requires a lot of practical studies and it is impossible to learn practical skills online. So in our study, we consider online education as a variety among other forms, which suggests of distance technologies in the usual educational process and involves systematic interaction between the object and the subject of pedagogical activity. The participants of the pedagogical process can be anywhere with access to the Internet, classes or consultations in real time, current control, providing educational disciplines with electronic content. To increase interest in the study of professional disciplines, the following forms of classes are offered: web quest, lecture-provocation, sharing an online board, online crossword puzzle, web relay, using a three-dimensional body model, using a random question selection method.

Distance learning plays an increasing role in modern education; it opens the access to non-traditional sources of information, increases the efficiency of self-dependent work, provides completely new opportunities for creativity, finding and consolidating various professional skills, and allows teachers to implement fundamentally new forms and methods of teaching. sports.

Keywords: distance technologies; professional disciplines; forms of online classes; physical culture and

П остановка проблеми. Пошуки оптимального методичного забезпечення освіти можна віднести до процесу систематичного та неперервного. 3 плином часу змінюються ізапити, іпроблеми, іпріоритети, йінтереси суспільства. Перед педагогами безупинно виникають нові вимоги, а саме: знайти підходи до сучасних здобувачів освіти, бути готовим до постійної самоосвіти і підвищення кваліфікаційного рівня, одночасно мати хист до творчого та нестандартного мислення та зуміти навчити цьому майбутнього фахівця, засвоювати комп'ютерні та інші новітні технології та ефективно впроваджувати новації в освітній 


\section{РІЗНОВИДИ ФОРМ ДИСТАНЦИЙНИХ ЗАНЯТЬ 3 ФАХОВИХ ДИСЦИПЛІН СПЕЦІАЛЬНОСТІ ФІЗИЧНА КУЛЬТУРА І СПОРТ}

процес тощо. Лише завдяки пристосованості до вимог та умов, що швидко змінюються, в освітньому середовищі можливо забезпечити потреби ринку праці у професіоналах найвищого рівня.

Система освіти, яка традиційно формується десятиліттями, за останні роки зазнала істотної модернізації, що пов'язано зі швидким та успішним розвитком інформаційних i телекомунікаційних технологій. Суттєві зміни традиційних освітніх комунікацій яскраво проявляються у системі дистанційного навчання.

У закладах фахової передвищої та вищої освіти наразі особлива увага надається саме дистанційній формі навчання та особливостям іiі функціонування. Це зумовлено низкою причин, серед яких як “вимушеність” дистанційного навчання через пандемію Covid-19 у всьому світі, так і привабливість дистанційної форми за певну зручність та мобільність у порівнянні 3 традиційним очним навчанням.

Аналіз останніх досліджень і публікацій. Дослідженням дистанційної освіти в Україні займалися вчені В. Биков, В. Бондаренко, I. Герасименко, Ю. Драгнєв, В. Кухаренко, П. Ладика, В. Олійник, Є. Полат, А. Сущенко та iH.

Наукові пошуки вивчення проблеми дистанційного навчання дали змогу трактувати це поняття 3 різних ракурсів: вважається об'єктивним наслідком процесу інформатизації і становлять перспективну, синтетичну, гуманістичну та інтегральну форми освіти [9]; технологія, що базується на принципах відкритого навчання, широко використовує комп'ютерні навчальні програми і з допомогою сучасних телекомунікацій створює освітнє середовище [1]; заочне навчання 3 використанням засобів комп'ютерних мереж [8]; комплекс освітніх послуг, що пропонуються здобувачам освіти через спеціалізоване телекомунікаційне інформаційне освітнє середовище, основу яких складає методологія, спрямована на індивідуальну роботу зі спеціальним структурованим навчальним матеріалом з різним ступенем спілкуванням між об'єктами (здобувачами освіти) і суб'єктами (викладачами, експертами тощо) освітнього процесу [5]; форма організації і реалізації освітнього процесу, в якому його учасники здійснюють навчальну взаємодію принципово екстериторіально [2].

Дистанційну форму освіти у дослідженні розглядаємо не як повноцінну і самодостатню форму навчання, а як різновид серед інших форм, який полягає у впровадженні дистанційних технологій у звичний освітній процес, та передбачає систематичну взаємодію між об'єктом і суб'єктом педагогічної діяльності, при цьому перебуваючи у будь-якому місці з доступом до мережі інтернету; заняття або консультації як у реальному часі, так і офлайн; регулярний поточний контроль; повне забезпечення навчальних дисциплін електронним контентом [7].

Отже, дистанційна форма навчання потребує методичного забезпечення дисциплін на принципово новому якісному рівні, із застосуванням інноваційних та інтерактивних засобів і методів.

Професійна підготовка майбутніх фахівців фізичної культури і спорту - специфічна галузь, що, безумовно, потребує у великому обсязі саме практичних занять. У сучасних реаліях підготовка таких фахівців активно вдосконалюється й модернізується.

Питання дистанційного навчання майбутніх фахівців фізичної культури і спорту розглядали у своїх дослідженнях науковці Е. Ахмедзянов, I. Гринченко, С. Гуменюк, О. Даниско, Н. Денисенко, О. Дмитрієв, Р. Клопов, О. Корносенко, О. Кучерявий, П. Петров, А. Сущенко, І. Тараненко, В. Томашевський, В. Шандригось та ін. Як виявилося, аналіз наукових джерел показав, що означена проблема все таки $\epsilon$ недостатньо дослідженою (передовсім, не вистачає результатів саме реалізації дистанційного навчання) і потребує постійного вивчення в умовах інтенсивного розвитку навчальних технологій.

Мета статті. Розглянути різновиди форм організації занять (на прикладі фахових дисциплін) при дистанційному навчанні майбутніх фахівців фізичної культури і спорту у ВСП “Економікоправничий фаховий коледж ЗНУ" з метою визначення доцільності їх використання та ефективності засвоєння навчального матеріалу здобувачами освіти.

Виклад основного матеріалу. Ефективність професійної підготовки майбутніх фахівців безпосередньо залежить від їх самомотивації та високого рівня самоорганізації, з одного боку, та можливостей закладу освіти та викладача впроваджувати принципово нові моделі навчання, що базуються на роботі 3 комп'ютерними технологіями, з іншого. Викладач покликаний розробити електронний контент 3 унікальним змістовим наповненням, проводити онлайнконсультації 3 використанням інтерактивної подачі матеріалу нестандартних завдань, скласти адаптовані комплекси вправ тощо. Тож, джерелом інформації в цих моделях є бази даних у віртуальному навчальному середовищі, викладач виступає у ролі координатора освітнього процесу, а здобувач 


\section{РІЗНОВИДИ ФОРМ ДИСТАНЦЙНИХЗАНЯТЬ 3 ФАХОВИХ ДИСЦИПЛІН}

СПЕЦАЛЬНОСТІ ФІЗИЧНА КУЛЬТУРА І СПОРТ

освіти - у ролі інтерпретатора знань. Отже, діяльність студента з пасивного отримання знань перетворюється на діяльність з їх активного пошуку.

Навчання з елементами дистанційної форми особливо актуальне для цієї галузі, адже специфіка спеціальності “фізична культура і спорт” полягає в одночасному навчанні студента і щільному графіку його тренувально-змагальних зборів. Тому дуже важливо мати можливість контакту “викладач-студент”, незалежно від місцезнаходження та виконання поточних навчальних завдань у будьякий зручний час для студента-спортсмена.

3 іншого боку, спеціальність “фізична культура і спорт" відрізняється від інших педагогічних спеціальностей тим, що професійно-орієнтовані дисципліни мають практичний характер, а тому актуалізується потреба отримані теоретичні знання доповнювати практичними уміннями у спортивних залах, на стадіонах, в басейнах тощо. Таким чином, перехід на повне дистанційне навчання для здобувачів освіти з цієї спеціальності неможливий.

3 огляду на вищесказане й активне повсюдне впровадження дистанційного навчання, фахова підготовка здобувачів освіти спеціальності “фізична культура і спорт” потребує нагального доопрацювання та вдосконалення з максимальним збереженням практичної спрямованості навчання

Дослідження проводилося протягом лютогоквітня 2021 р. серед здобувачів освіти спеціальності “фізична культура і спорт” II (41 студент) та III (27 студентів) курсів. Дослідження полягало у розробці, впровадженні та перевірці ефективності комплексу методів для дистанційного навчання.

Авторській розробці передував аналіз наявних розробок, методів, позитивного досвіду 3 проблеми від українських науковців, педагогів I. Большакової [3], В. Гейтенка [4], О. Даниско, О. Корносенко, І. Тараненко [6], Н. Терентьєвої [10].

Комплекс авторської розробки передбачав форми занять (форми викладу матеріалу), що доцільно застосовувати у професійній підготовці майбутніх фахівців фізичної культури і спорту. Це:

- веб-квест - створення інструкції з поетапними завданнями (останнє має бути 3 певним словом чи фразою). Допустиме використання вебресурсів. Студенти наввипередки проходять квест (наприклад, на занятті з дисципліни “Теорія і методика фізичної культури”: розв’язати задачу на розрахунок загальної щільності уроку відповідь на попереднє завдання буде сторінкою певного навчального посібника, на якій треба знайти три ключові слова у тексті, які треба трактувати чи охарактеризувати; на занятті 3 дисципліни "Харчування": виконати розрахунок добової норми калорій для спортсмена за заданими параметрами (вага, зріст, вік, стать) від відповіді на попереднє завдання треба відняти калорійність певних продуктів харчування за 100 гр. - визначити, який макроелемент за порядковим номером в таблиці Менделєєва вийшов - описати його тощо);

- лекція-провокація - навмисне допущення помилок під час лекції (наприклад, на занятті 3 дисципліни “Футбол з методиками викладання” неправильно пояснити правила гри; на занятті з дисципліни “Вступ до спеціальності” переплутати підписи прізвищ до фотографій видатних спортсменів тощо). Викладач може попередити студентів, щоб були уважними і знаходили помилки, а може діяти без попередження (робити паузи після так званих провокацій). У кінці заняття заохочуються найуважніші слухачі;

- спільне використання онлайндошки можливість писати або малювати у реальному часі, використовуючи демонстрацію екрана (наприклад, на занятті з дисципліни "Гімнастика 3 методиками викладання" дати завдання студентам кожному за чергою схематично зобразити / замалювати гімнастичні стійки; на занятті з дисципліни “Гандбол з методиками викладання" за чергою доповнювати схему “Техніка і тактика гандболу” тощо);

- онлайн-кросворд - розв'язання усього кросворду на час або по одному слову за чергою (наприклад, на занятті з дисципліни “Фізіологія спорту” кросворд у кінці заняття як перевірка засвоєння нового матеріалу або навпаки - на початку як перевірка домашнього завдання; на занятті з дисципліни “Педагогіка” кросворд паралельно з поясненням нової теми - вивчили поняття - знайшли його місце у кросворді тощо);

- веб-естафета - відповідь студента на питання та задавання питання наступному студенту, ніби передаючи один одному естафету (наприклад, на занятті 3 дисципліни “Легка атлетика 3 методиками викладання” питання 3 видів та техніки стрибків; на занятті $з$ дисципліни “Туризм 3 методиками викладання" питання щодо видів туризму тощо); на занятті з дисципліни “Масаж” розробити алгоритм проведення масажу за запитом клієнта тощо);

- використання тримірної моделі частин тіла наочні електронні посібники (наприклад, на занятті з дисципліни “Анатомія” пояснення нової теми із синхронною візуалізацією на анатомічному атласі; на занятті з дисципліни “Атлетизм” 


\section{РІЗНОВИДИ ФОРМ ДИСТАНЦЙНИХ ЗАНЯТЬ 3 ФАХОВИХ ДИСЦИПЛІН СПЕЦІАЛЬНОСТІ ФІЗИЧНА КУЛЬТУРА І СПОРТ}

демонстрація м'язів, що працюють під час виконання тієї чи тієї вправи тощо);

- відео- та мультимедіалекції, відеопрезентації, онлайн-тренажери, онлайн-тести, опитування 3 використанням рандомного способу вибору питання тощо;

- адаптовані комплекси вправ для виконання в умовах обмеженої площі (переважно в домашніх умовах) з різних видів спорту (наприклад, на занятті 3 дисципліни “Легка атлетика 3 методиками викладання" підготовчі вправи для засвоєння техніки або елементів техніки видів легкої атлетики (спортивна ходьба, низький старт, спеціальні вправи легкоатлета та ін.); на занятті 3 дисципліни "Настільний теніс" вправи на володіння м'ячиком та координацію рухів тощо.

Безсумнівно, проводити повноцінне навчання рухових навичок неможливо в умовах дистанційної форми, однак 3 кожної практичної дисципліни можливо підібрати такий комплекс вправ, який реально і безпечно виконати поза закладом освіти.

Заняття 3 використанням запропонованих методів із розробленого комплексу проводились протягом трьох місяців дистанційного навчання. Критеріємефективностізастосуваннявищеперерахованих методів уважаємо показник успішності (кількість академічних заборгованостей), рівень засвоєння дисциплін (співвідношення високого / середнього / достатнього / низького рівня) та сформованість зацікавленості безпосередньо у здобувачів освіти (за допомогою анкетування).

Результати дослідження дають підстави стверджувати:

- показник успішності сягнув позначки $100 \%$ на III курсі та 92 \% на II курсі (8 \% студентів за результатами сесії мали академічні заборгованості з фахових дисциплін);

- рівні засвоєння фахових дисциплін розподілилися так: високого (оцінка “відмінно") досягли $23 \%$ здобувачів освіти, середнього (оцінка “добре”) - 37 \%, достатнього (оцінка “задовільно”) - 40 \%, низького рівня (оцінка “незадовільно”) - 8 \%;

- зацікавленість у вивченні фахових дисциплін за рахунок використання розроблених методів підвищилася, про що свідчать такі відповіді респондентів (здобувачів освіти): на питання “Оцініть за п'ятибальною шкалою рівень зацікавленості вивчення фахових дисциплін під час дистанційного навчання" 84 \% поставили оцінку "5", $10 \%-" 4 ", 4 \%-$ - 3 ".

Висновки та перспективи подальших досліджень. Підсумовуючи, можемо констатувати, що сучасна система дистанційної освіти, безперечно, має низку суттєвих переваг. Це навчання в індивідуальному темпі, мобільність, територіальна незалежність, різноманіття форм організації занять, можливість ефективного зворотного зв'язку та ін. Завдяки методичним прийомам та інтерактивним розробкам викладачів різних дисциплін, можливо підвищити зацікавленість здобувачів освіти до вивчення навчального матеріалу, і, відповідно, підвищувати ефективність навчання загалом.

Однак професійна підготовка майбутніх фахівців фізичної культури і спорту не може обмежуватися використанням технологій лише дистанційного навчання. Неможливо віртуально повноцінно оволодіти технікою рухів, засвоїти техніку та тактику спортивних ігор, скласти контрольні нормативи, оволодіти методикою викладання та ін. Майбутнє - за змішаними формами навчання, де поруч $з$ дистанційними обов'язково проходять практичні заняття під керівництвом викладача.

\section{ЛІТЕРАТУРА}

1. Андрусенко Н. В. Дистанційне навчання в Україні. Дистанційне навчання як сучасна освітня технологія : матеріали міжвуз. вебінару (м. Вінниця, 31 берез. 2017 р.) / відп. ред. Л. Б. Ліщинська. Вінниця : ВТЕІ КНТЕУ, 2017. С. 7-10.

2. Биков В. Ю. Моделі організаційних систем відкритої освіти. Київ: Атіка, 2009. 684 с.

3. Большакова I. Огляд практик дистанційного навчання. Запис онлайн-трансляції. URL:https:// nus.org.ua/articles/praktyky-ta-pidhody-dodystantsijnogo- navchannya-rekomendatsiyi-dlyavchyteliv/

4. Гейтенко В.В., Сорокін Ю.С. Організаційнопедагогічні умови дистанційних технологій навчання зі студентами спеціальності “фізична культура i спорт”. URL: $\underline{\text { http:// }}$ www.innovpedagogy.od.ua/archives/2020/29/part 1/ 20.pdf

5. Герасименко I. В. Система підтримки дистанційного навчання як складова інформаційного середовища ВНЗ. Проблеми сучасної педагогічної освіти: зб. ст. Ялта: РВВ КГУ, 2013. Вип. 40, ч. 4. С. 22-30.

6. Даниско О., Корносенко О., Тараненко I. Специфіка та перспективи використання дистанційних технологій у процесі професійної підготовки майбутніх фахівців з фізичної культури і спорту. Екстрене дистанційне навчання в Україні: Монографія / За ред. В.М. Кухаренка, В.В. Бондаренка. Харків:. Вид-во КП “Міська друкарня", 2020. С.185-197.

7. Конох А., Багорка А., Напалкова Т. Використання 


\section{РІЗНОВИДИ ФОРМ ДИСТАНЦЙНИХ ЗАНЯТЬ 3 ФАХОВИХ ДИСЦИПЛІН СПЕЦІАЛЬНОСТІ ФІЗИЧНА КУЛЬТУРА І СПОРТ}

дистанційних технологій у професійній підготовці майбутніх фахівців фізичної культури і спорту. Наукові записки Бердянського державного педагогічного університету. Серія : Педагогічні науки : зб. наук. пр. Вип.2. Бердянськ : БДПУ, 2020. C.289-300.

8. Ладика П. І. Дистанційне навчання в системі підготовки фахівців з фізичної культури і спорту. Науковий часопис Національного педагогічного університету імені М.П. Драгоманова. Серія № 15. “Науково-педагогічні проблеми фізичної культури / Фізична культура і спорт”. Зб. наукових праць / За ред. Г.М. Арзютова. Київ: Вид-во НПУ імені М.П. Драгоманова, 2015. Випуск 5 К (61) 15. С. 270-273.

9. Сущенко А.В. Інформаційно-комунікаційні технології і засоби навчання в професійній підготовці майбутніх фахівців фізичного виховання і спорту. Вісник Запорізького національного університету. Серія "Фізичне виховання $i$ cnopm”. 2012. № 1 (7). С. 104-111.

10. Терентьєва Н. О. Особливості дистанційної підготовки магістрантів факультетів фізичної культури. Інформаційні технології $i$ засоби навчання, 2019, Том 69, №1. С.139-148.

\section{REFERENCES}

1. Andrusenko, N. V. (2017). Dystantsiine navchannia v Ukraini [Distance learning in Ukraine]. Dystantsiine navchannia yak suchasna osvitnia tekhnolohiia : materialy mizhvuz. vebinaru ( $m$. Vinnytsia, 31 berez. 2017 r.) - Distance learning as a modern educational technology: Interuniversity Proceedings Webinar (Vinnytsia, March the $31^{\text {st }}$, 2017). (Ed.). L. B. Lishchynska. Vinnytsia, pp. 710. [in Ukrainian].

2. Bykov, V. Yu. (2009). Modeli orhanizatsiinykh system vidkrytoi osvity [Models of organizational systems of open education]. Kyiv, 684 p. [in Ukrainian].

3. Bolshakova, I. Ohliad praktyk dystantsiinoho navchannia [Review of distance learning practices]. Record an online broadcast. Available at: https:// nus.org.ua/articles/praktyky-ta-pidhody-dodystantsijnogo- navchannya-rekomendatsiyi-dlyavchyteliv/ [in Ukrainian].

4. Heitenko, V.V. \& Sorokin, Yu.S., Orhanizatsiinopedahohichni umovy dystantsiinykh tekhnolohii navchannia zi studentamy spetsialnosti "fizychna kultura i sport" [Organizational and pedagogical conditions of distance learning technologies with students majoring in "physical culture and sports"]. Available at: http://www.innovpedagogy.od.ua/ archives/2020/29/part_1/20.pdf [in Ukrainian].

5. Herasymenko, I. V. (2013). Systema pidtrymky dystantsiinoho navchannia yak skladova informatsiinoho seredovyshcha VNZ [Distance learning support system as a component of the university information environment]. Problems of modern pedagogical education: coll. of articles.Yalta, Vol. 40, part. 4. pp. 22-30. [in Ukrainian].

6. Danysko, O., Kornosenko, O. \& Taranenko, I. (2020). Spetsyfika ta perspektyvy vykorystannia dystantsiinykh tekhnolohii $\mathrm{u}$ protsesi profesiinoi pidhotovky maibutnikh fakhivtsiv $z$ fizychnoi kultury $i$ sportu [Specifics and prospects of using remote technologies in the process of professional training of future specialists in physical culture and sports]. Emergency distance learning in Ukraine: Monograph. (Ed.). V.M. Kukharenko, V.V. Bondarenko. Kharkiv, pp.185-197. [in Ukrainian].

7. Konokh, A., Bahorka, A. \& Napalkova, T. (2020). Vykorystannia dystantsiinykh tekhnolohii u profesiinii pidhotovtsi maibutnikh fakhivtsiv fizychnoi kultury i sportu. Naukovi zapysky Berdianskoho derzhavnoho pedahohichnoho universytetu [The use of remote technologies in the training of future specialists in physical culture and sports]. Scientific notes of Berdyansk State Pedagogical University. Series: Pedagogical sciences: coll. Science. works. Vol.2. Berdiansk, pp.289-300. [in Ukrainian].

8. Ladyka, P. I. (2015). Dystantsiine navchannia v systemi pidhotovky fakhivtsiv z fizychnoi kultury $i$ sportu [Distance learning in the system of training specialists in physical culture and sports]. Scientific journal of the National Pedagogical University named after Mykhaylo Drahomanov. Series No. 15. "Scientific and pedagogical problems of physical culture / Physical culture and sports". Coll. scientific works. (Ed.). H.M. Arziutova. Kyiv, Vol. 5 K (61) 15. pp. 270-273. [in Ukrainian].

9. Sushchenko, A.V. (2012). Informatsiinokomunikatsiini tekhnolohii i zasoby navchannia $\mathrm{v}$ profesiinii pidhotovtsi maibutnikh fakhivtsiv fizychnoho vykhovannia i sportu [Information and communication technologies and teaching aids in the training of future specialists in physical education and sports]. Bulletin of Zaporizhzhya National University. Series "Physical Education and Sports". No. 1 (7). pp. 104-111. [in Ukrainian].

10. Terentieva, N. O. (2019). Osoblyvosti dystantsiinoi pidhotovky mahistrantiv fakultetiv fizychnoi kultury [Features of distance training of undergraduates of faculties of physical culture]. Information technologies and teaching aids. Vol. 69, no.1, pp.139-148. [in Ukrainian].

Стаття надійшла до редакції 15.10.2021 